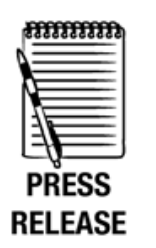

Paediatric Intensive Care Unit, Southampton General Hospital, Southampton, England ${ }^{2}$ University of Leicester, Leicester, England ${ }^{3}$ Emergency Department, Leicester Royal Infirmary, Leicester, England ${ }^{4}$ Helicopter retrieval services, Ambulance Service of New South Wales, Australia ${ }^{5}$ Paediatric Intensive Care Unit, Birmingham Children's Hospital, Birmingham, England

\section{Correspondence to}

Philip Hyde, Paediatric Intensive Care Unit, Southampton General Hospital, Tremona Road, Southampton S016 6YD, UK; prhyde@doctors.org.uk

Accepted 3 January 2011 Published Online First 21 March 2011

\section{(2) UNLOCKID}

This paper is freely available online under the BMJ Journals unlocked scheme, see http:// emj.bmj.com/site/about/ unlocked.xhtml

\title{
Availability and utilisation of physician-based pre-hospital critical care support to the NHS ambulance service in England, Wales and Northern Ireland
}

\author{
Philip Hyde, ${ }^{1}$ Rod Mackenzie, ${ }^{2}$ Gail $\mathrm{Ng}^{3}{ }^{3}$ Cliff Reid, ${ }^{4}$ Gale Pearson ${ }^{5}$
}

\section{ABSTRACT}

Background Every day throughout the UK, ambulance services seek medical assistance in providing critically ill or injured patients with pre-hospital care.

Objective To identify the current availability and utilisation of physician-based pre-hospital critical care capability across England, Wales and Northern Ireland. Design A postal and telephone survey was undertaken between April and December 2009 of all 13 regional NHS ambulance services, 17 air ambulance charities, 34 organisations affiliated to the British Association for Immediate Care and 215 type 1 emergency departments in England, Wales and Northern Ireland. The survey focused on the availability and use of physician-based pre-hospital critical care support.

Results The response rate was 100\%. Although nine NHS ambulance services recorded physician attendance at 6155 incidents, few could quantify doctor availability and utilisation. All but one of the British Association for Immediate Care organisations deployed 'only when available' and only $45 \%$ of active doctors could provide critical care support. Eleven air ambulance services (65\%) operated with a doctor but only $5(29 \%)$ operated 7 days a week. Fifty-nine EDs (27\%) had a pre-hospital team but only $5(2 \%)$ had $24 \mathrm{~h}$ deployable critical care capability and none were used regularly.

Conclusion There is wide geographical and diurnal variability in availability and utilisation of physician-based pre-hospital critical care support. Only London ambulance service has access to NHS-commissioned $24 \mathrm{~h}$ physician-based pre-hospital critical care support. Throughout the rest of the UK, extensive use is made of volunteer doctors and charity sector providers of varying availability and capability.

\section{INTRODUCTION}

Following the NHS Next Stage Review, ${ }^{1}$ a number of highly critical reports ${ }^{2}$ and the appointment of a national clinical director for trauma care, the Department of Health initiated the development of regional networks for the management of major trauma. ${ }^{4}$

The trauma network is intended to encompass all elements of the patient's journey from injury to rehabilitation-including the average $55 \mathrm{~min}$ pre-hospital phase. ${ }^{2}$ There is increasing public, professional and political recognition that physician-based critical care during this phase is associated with increased survival for selected patients. ${ }^{5-10}$ There is also a sense of inequity in access to, and availability of, physician-based, on-scene medical support to the ambulance service. Many consider that levels of clinical care for the critically injured should be equitable and consistent irrespective of geography or time of day or whether the patient is at the scene, in-transit to hospital or in an emergency department-critical care being a clinical process and not a physical place. ${ }^{211} 12$ The recent recommendation from the Major Trauma Clinical Advisory Groups for $24 \mathrm{~h}$ deployable 'enhanced care' teams to provide critical care support to ambulance services reflects these views. ${ }^{13}$

To assist with the development of the prehospital component of the evolving trauma networks, we sought to identify the current availability and utilisation of physician-based prehospital critical care services across England, Wales and Northern Ireland.

\section{METHODS}

Between April and July 2009, we conduced a postal survey of all 13 regional NHS ambulance services, 17 air ambulance charities and 34 organisations affiliated to the British Association for Immediate Care (BASICS) operating in England, Wales and Northern Ireland. The survey was constructed and distributed as a freedom of information request and covered the topics listed in box 1. Follow-up was by repeat letter and, where necessary, telephone contact with the relevant clinical lead.

We then conducted a telephone survey between September and December 2009 of all 215 major (type 1) emergency departments (EDs) listed in Department of Health statistical returns. The survey was administered by one author (GN) to senior medical staff (consultant or registrar) on two separate occasions and comprised four questions about the specific capability of the ED at the time of the call (box 2).

The ability of the service and/or individual doctors to provide pre-hospital emergency anaesthesia was used as a surrogate marker of "critical care' capability-defined by the Department of Health as the provision of organ support and intensive monitoring. ${ }^{14}$

Results were expressed as counts and simple proportions and integrated into maps of physician-based pre-hospital critical care provision.

\section{RESULTS}

The response rate was 100\% for all surveys. Table 1 shows the aggregated information provided by the 


\section{Box 1 Topics included in the postal survey}

\section{NHS ambulance trusts}

- Number of pre-hospital immediate care doctors available to the Ambulance service

- Number of activations of pre-hospital care doctors

- Number of scene attendances by pre-hospital care doctors for 2007 and 2008.

British Association for Immediate Care Schemes (BASICS)

- Exact geographical area of operational activities

- Number of doctors clinically active in pre-hospital care

- Professional background of each clinically active member and number that provide pre-hospital emergency anaesthesia and intubation unsupervised (as a measure of critical care capability)

- Availability of pre-hospital care in daylight hours and at night time

- Funding source for activities.

\section{Air ambulance}

- Geographical area covered

- Number of aircraft used

- Hours of operation

- Whether a clinical service was provided in the hours of darkness (when air ambulances are usually unavailable)

- Number of days a week a doctor was present as part of the crew

- Number of doctors that provide pre-hospital emergency anaesthesia and intubation unsupervised (as a measure of critical care capability)

- Funding source for doctors.

respondents. Of the 13 ambulance services, only three knew how many doctors were available to support their service. These responses did not correlate with the number of active prehospital doctors reported by the BASICS schemes in the same region. Five ambulance services separately recorded requests for doctors (3720 and 4651 incidents in 2007 and 2008, respectively). Nine services recorded actual scene attendance (5008 and 6155 attendances in 2007 and 2008, respectively). These numbers reflect recorded utilisation of pre-hospital doctors with and without critical care skills as this distinction was not recorded by the services. The absence of utilisation data from 10 services contradicts the experience of BASICS schemes and air ambulance services active in those areas and indicates significant under-reporting. Further detailed analysis of activity data was not undertaken.

Box 2 Topics included in the emergency department telephone survey

- Whether the hospital had a system for deploying a medical team if the ambulance service asked for assistance with a trapped injured patient (ie, pre-arranged plan, dedicated equipment, pre-allocated trained staff, mechanism for activation agreed with ambulance service).

- Whether that team, if available, had the skills to provide prehospital emergency anaesthesia.

- Whether that team was usually available $24 / 7$.

- If a team was available, how often the team was deployed.
All 34 organisations affiliated to BASICS are charity funded and all but one reported deploying 'only when available' rather than routinely within defined operating hours. None have a guaranteed $24 \mathrm{~h}$ service and only one operated routinely into the night as a scheduled service. Of the 327 volunteer doctors operating in these schemes, $146(45 \%)$ reported anaesthetic capability. Four schemes (12\%) deployed critical care capability at every incident but, in contrast, 11 (32\%) reported no deployable critical care capability at all.

Eleven of the 17 air ambulance charity services (65\%) operated with a doctor on one or more of their 30 aircraft but only five (29\%) operated 7 days a week. In many services, doctor availability on any one day was unpredictable-with $76 \%$ relying on volunteer staffing (paid or unpaid) to varying degrees. Critical care capability is often assumed when doctors staff air ambulances but many services employ doctors who do not have these skills. It was not possible to quantify this. Only one of the air ambulance charities continued to operate routinely with a doctor into the night (using a response car and NHSfunded medical staff)-all others were restricted to daylight operations.

Figure 1 illustrates the distribution of physician-based prehospital critical care availability from BASICS schemes and air ambulance services according to ambulance service area of operations.

Fifty-nine of the $215 \mathrm{ED}(27 \%)$ had a system in place for $24 \mathrm{~h}$ deployment of a pre-hospital care team but only five (2\%) had the skills to provide pre-hospital emergency anaesthesia. All teams reporting this capability also stated that they had infrequently or never been deployed.

\section{DISCUSSION}

There are a number of limitations to this survey. The distribution of volunteer-based pre-hospital services is dynamic and thus our results may not precisely reflect the current situation. There are also artificial borders between the NHS ambulance service regions on figure 1 and we recognise that there is more flexibility in cross-cover arrangements than may be implied by our aggregation of survey responses. We also identified that BASICS organisations, air ambulance charities and EDs are, in many cases, interlinked. This may result in an over-count of the number of services and doctors able to provide critical care. There have, however, been no major organisational, policy or funding changes within the regions that would dramatically alter the overall picture of extensive geographical and diurnal variability and inequity in the provision of physician-based pre-hospital critical care in the UK. The results reflect the view expressed by the Royal College of Surgeons to parliament in $2008^{6}$ :

'there is great inequality in access to, and provision of, pre-hospital critical care. As a consequence, there are preventable pre-hospital and early-hospital deaths that could have been averted had there been access to appropriate services'

Although a survival advantage has been demonstrated for severely injured patients treated by physician-based pre-hospital critical care teams operating within an organised system of care, ${ }^{11} 12$ 15-22 considerable debate remains about their role and cost effectiveness. ${ }^{5}$

Only in a few cases and places can critically injured patients who might benefit from such care receive it from NHScommissioned pre-hospital critical care physician-based teams. The inequity is striking (figure 1). Only one NHS-commissioned physician-based service exists and operates (London). Five of the regional air ambulance charities provide non-NHS regional 
Table 1 Aggregated survey results showing variability in data collection, availability, capability and utilisation of pre-hospital critical care resources. No hospital with a medical team able to provide $24 / 7$ critical care reported deployment four or more times a month. Note that London HEMS, an air ambulance service able to provide $24 / 7$ critical care, based at the Royal London Hospital, is recorded as operating independently from the emergency department

\begin{tabular}{|c|c|c|c|c|c|c|c|c|c|c|c|c|}
\hline \multicolumn{6}{|c|}{ NHS Ambulance service survey } & \multicolumn{3}{|c|}{ BASICS survey } & \multicolumn{2}{|c|}{ Air ambulance survey } & \multicolumn{2}{|c|}{$\begin{array}{l}\text { Hospital emergency } \\
\text { department survey }\end{array}$} \\
\hline \multirow{2}{*}{$\begin{array}{l}\text { Ambulance } \\
\text { service NHS } \\
\text { trust }\end{array}$} & \multirow{2}{*}{$\begin{array}{l}\text { Doctors } \\
\text { available (n) }\end{array}$} & \multicolumn{2}{|c|}{$\begin{array}{l}\text { Doctors } \\
\text { requested } \\
\text { (incidents) }\end{array}$} & \multicolumn{2}{|c|}{$\begin{array}{l}\text { Doctors } \\
\text { attended } \\
\text { (incidents) }\end{array}$} & \multirow{2}{*}{$\begin{array}{l}\text { BASICS } \\
\text { affiliated } \\
\text { schemes } \\
\text { (n) }\end{array}$} & \multirow{2}{*}{$\begin{array}{l}\text { Doctors in } \\
\text { schemes } \\
\text { (n) }\end{array}$} & \multirow{2}{*}{$\begin{array}{l}\text { Critical care } \\
\text { capable ( } \% \\
\text { of doctors) }\end{array}$} & \multirow{2}{*}{$\begin{array}{l}\text { Air ambulance } \\
\text { operations (n) }\end{array}$} & \multirow{2}{*}{$\begin{array}{l}\text { Estimated } \\
\text { doctor } \\
\text { availability } \\
\text { (days/ week) }\end{array}$} & \multirow{2}{*}{$\begin{array}{l}\text { Pre-hospital } \\
\text { team } 24 / 7 \\
\text { (number of } \\
\text { departments) }\end{array}$} & \multirow{2}{*}{$\begin{array}{l}\text { Critical care } \\
\text { capability } \\
\text { (number of } \\
\text { departments) }\end{array}$} \\
\hline & & 2007 & 2008 & 2007 & 2008 & & & & & & & \\
\hline South Western & Not known & 380 & 430 & 309 & 369 & 4 & 17 & 0 & 4 & 0 & 3 & 0 \\
\hline South Central & Not known & - & - & 770 & 966 & 4 & 27 & 81 & 2 & $2-3$ & 5 & 1 \\
\hline South East Coast & Not known & - & - & 672 & 785 & 1 & 16 & 19 & 2 & 7 & 2 & 0 \\
\hline London & Not known & - & - & - & - & 1 & 12 & 100 & 1 & 7 & 1 & 0 \\
\hline Wales & Not known & - & - & - & - & 2 & 10 & 50 & 3 & 0 & 7 & 1 \\
\hline Great Western & Not known & 156 & 113 & 118 & 71 & 3 & 18 & 28 & 1 & 0 & 1 & 0 \\
\hline West Midlands & Not known & 2401 & 2869 & 1423 & 1693 & 4 & 46 & 61 & 3 & 3 & 6 & 1 \\
\hline East Midlands & Not known & - & - & 1122 & 1324 & 3 & 25 & 48 & 3 & $6-7$ & 12 & 0 \\
\hline East of England & Not known & - & - & - & - & 5 & 72 & 51 & 4 & 7 & 4 & 0 \\
\hline North West & 42 & 630 & 497 & 437 & 335 & 4 & 27 & 30 & 2 & 0 & 9 & 1 \\
\hline North East & 1 & - & - & 6 & 6 & 1 & 3 & 0 & 3 & 7 & 1 & 0 \\
\hline Yorkshire & 38 & 153 & 742 & 151 & 606 & 1 & 45 & 24 & 2 & 2 & 6 & 0 \\
\hline Northern Ireland & Not known & - & - & - & - & 1 & 9 & 33 & 0 & 0 & 2 & 1 \\
\hline
\end{tabular}

physician-based pre-hospital critical care services during the day. The populations served by these services have access to a completely different level of care than the rest of the country. The remaining population can only access similar care when a volunteer doctor able to provide critical care is available to support their NHS ambulance trust, BASICS scheme and local air ambulance. This provision largely depends on volunteer doctors and cover is therefore incomplete, unpredictable and inconsistent. The situation is much worse at night (figure 1B). It is unsurprising that the National Confidential Enquiry into Patient Outcome and Death ${ }^{2}$ concluded that: 'The current structure of prehospital management is insufficient to meet the needs of the severely injured patient'.
Figure 1 also highlights the existence of large areas of the country in which there is no guarantee of receiving physicianbased pre-hospital critical care at any time. We emphasise the word 'guarantee'. We recognise that there are individuals and organisations within these areas who are capable of providing pre-hospital critical care support and frequently do so when available. Indeed, the differences in social and physical geography across the UK necessitate differences in the structure of pre-hospital care provision. However, the medical requirements of the critically injured are independent of their injury location or time. The NHS constitution's principle of 'access to services being based on clinical need ${ }^{23}$ is clearly not being applied to the critically injured before they reach hospital.
Figure 1 Pre-hospital physician-based critical care provision. (A) Daylight hours. (B) Hours of darkness (at night time the two dedicated services do not cover the whole night 7 days a week).
A

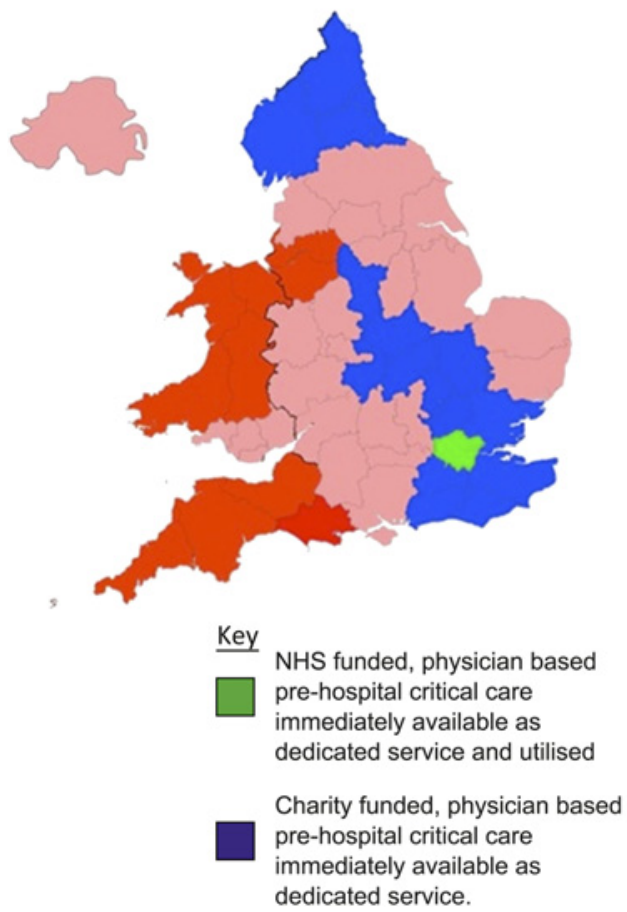

B
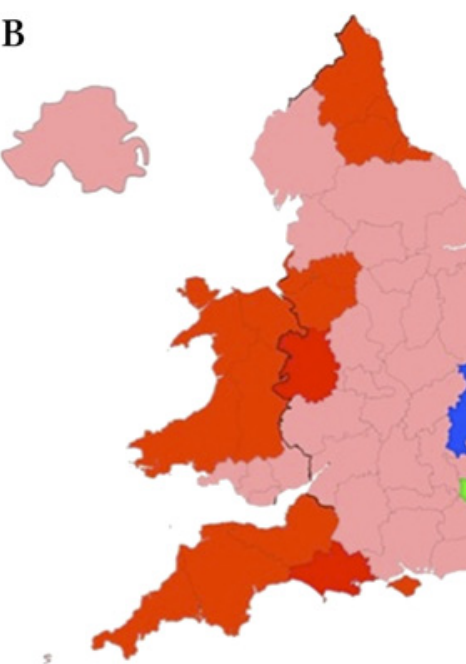

Charity funded, physician based

pre-hospital critical care possibly available (no dedicated service).

No physician based pre-hospital critical care available. 
A nationwide development of regional trauma networks is currently underway. In order for trauma systems to function, patients must be transported safely to major trauma centres. This requires clinicians with the ability to triage and safely transport the critically injured. In hospitals and between hospitals, critical care physician-led teams exclusively carry out this role. This survey shows that outside hospital, the NHS does not provide physician-based critical care to facilitate this.

The use of volunteer doctors to fill this gap in service provision is considerable, with 6155 recorded scene attendances in 2008 and true activity levels that are likely to be much greater. The call for these doctors indicates that NHS ambulance services recognise a cohort of patients whose needs exceed their capabilities. ${ }^{5}$ If all 13 ambulance services had reported similar levels of physician utilisation, this would equate to nationwide crude minimum estimates of the order of 13000 requests and 9500 scene attendances a year. The lack of data from ambulance trusts about whether these doctors were all able to provide critical care inevitably means that this may be an overestimate. These are also small numbers in relation to overall urgent and unscheduled care demand. They do, however, represent a significant potential pre-hospital critical care workload which needs further delineation. We support the recent National Audit office recommendation that: "ambulance trusts should collect data on the resources dispatched and treatment provided, and link it with data collected by NHS acute trusts in order to monitor the quality and safety of care provided in the pre-hospital environment". We would emphasise that such data should include air ambulance activity data as well as the capability of any deployed physicians. Helicopter emergency ambulance service activity in the UK was reviewed in a postal survey in 2001 but services have evolved considerably since then and no unified capability or operational activity data source exists. ${ }^{24}$

There is also considerable variation in the availability of doctors with emergency anaesthetic skills and disordered patterns of use of this capability. Pre-hospital care doctors come from a range of backgrounds, including general practice, emergency medicine, surgery, anaesthesia and intensive care medicine. There are many aspects of pre-hospital care beyond organ support for the critically injured and ill. We particularly focused on pre-hospital critical care in this survey, as it is within this domain that the balance of evidence of benefit is strongest ${ }^{22}$ and the inequity of access most striking.

No major ED regularly deploys a team able to provide critical care and only 15 described a pre-planned system to deploy any form of $24 \mathrm{~h}$ team. If neither a major ED nor an ambulance service can easily access this capability for incidents involving one or two critically injured patients then they will struggle to access deployable critical care support for larger multi-casualty incidents. This brings the recent NHS Emergency Planning Guidance on the widespread provision of major emergency response incident teams (MERIT) into sharp focus. ${ }^{25}$ The guidance states that:

\begin{abstract}
'The scope of incidents that would warrant a MERIT response would include any incident where ambulance personnel at scene attending an incident identify a potential benefit, following assessment and triage, of having specialist or advanced clinical care at scene and decision making and critical interventions for adults and children.'
\end{abstract}

The Clinical Advisory Group on Trauma recently highlighted the obvious skills overlap between MERIT requirements and provision of accessible pre-hospital critical care. ${ }^{13}$ One solution may be to combine funding streams for MERIT and pre-hospital 'enhanced care' provision to ensure a regional $24 / 7$ pre-hospital critical care support capability. This would meet day to day ambulance demand while also acting as the first medical component of a response to a disaster. Innovative integration of our national need for pre-hospital critical care and major incident provision could provide the economic efficiency required for development of the pre-hospital 'enhanced care' component of our newly developing trauma systems.

Competing interests $\mathrm{PH}$ is a consultant in paediatric intensive care in Southampton clinical leadership fellow for South Central trauma system project and training office for the charity BASICS Hampshire. GN is a specialist registrar in emergency medicine in Leicester and a pre-hospital physician with the MAGPAS Emergency Medical Team. $\mathrm{RM}$ is a consultant and senior lecturer in emergency medicine in Leicester, the medical director of the emergency medical charity, Magpas, a member of BASICS, the Faculty of Pre-hospital Care and the Department of Health's Transport of the Critically III and Pre-hospital and Inter-hospital Transfer working groups. He also chairs the curriculum, training and assessment subcommittee of the Intercollegiate Board for Training in Pre-hospital Emergency Medicine. GP is a consultant in paediatric intensive care in Birmingham and is the clinical director of the ongoing National Confidential Enquiry into Head injury in Children. CR is a consultant in emergency medicine in Sydney, Australia and former chairman of BASICS Hampshire.

Contributors The authors would like to thank Antonis Papasolomontos for his assistance in data collection. This study was presented as a poster at the Retrieval 2010 conference, Glasgow.

Provenance and peer review Not commissioned; externally peer reviewed.

\section{REFERENCES}

1. Secretary of State for Health. High Quality Care For All: NHS Next Stage Review Final Report (Cm 7432). London: The Stationary Office, 2008. http://www.dh.gov.uk/ en/Publicationsandstatistics/Publications/PublicationsPolicyAndGuidance/DH_085825

2. Findlay G, Martin IC, Smith M, et al. Trauma: Who Cares? A report of the National Confidential Enquiry into Patient Outcome and Death. London: NCEPOD, 2007. http:// www.ncepod.org.uk/2007report2/Downloads/SIP_summary.pdf

3. The Royal College of Surgeons of England and the British Orthopaedic Association. Better Care for the Severely Injured. London: RCSE, 2000. http://www. rcseng.ac.uk/publications/docs/severely injured.html

4. The Intercollegiate Group on Trauma Standards. Regional Trauma Systems. Interim Guidance for Commissioners. London: RCSE, 2009. http://www.rcseng.ac.uk/ news/docs/Regional trauma systems.pdf

5. Mackenzie R, Stee- A, French J, et al. Views regarding the provision of prehospital critical care in the UK. Emerg Med J 2009;26:365-70.

6. House of Commons debate, 11 June 2008, c67WH. http://www.publications. parliament.uk/pa/cm200708/cmhansrd/cm080611/halltext/80611h0001. htm\#08061199000477

7. House of Lords Debate, 23 March 2009, c518. http://www.publications.parliament. uk/pa/ld200809/ldhansrd/text/90323-0011.htm\#09032337000020

8. National Audit Office. Major Trauma Care in England. London: The Stationery Office, 2010. http://www.nao.org.uk/publications/0910/major trauma care.aspx

9. Association of Anaesthetists of Great Britain and Ireland. $A A \overline{G B} /$ Safety Guideline: Pre-hospital Anaesthesia. London: AAGBI, 2009. http://www.aagbi.org/ publications/guidelines/docs/prehospital_glossy09.pdf

10. Hyde $\mathbf{P}$, Morris KE. Improving the outcome of severely head injured children in the UK. Paediatr Child Health 2009:19:487-91.

11. Garner A, Crooks J, Lee A, et al. Efficacy of prehospital critical care teams for severe blunt head injury in the Australian setting. Injury 2001;32:455-60.

12. Oppe S, De Charro FT. The effect of medical care by a helicopter trauma team on the probability of survival and quality of life of hospitalised victims. Accid Anal Prevention 2001;33:129-38.

13. Department of Health. NHS Clinical Advisory Groups Report. Regional Networks for Major Trauma. 2010. http://www.excellence.eastmidlands.nhs.uk/welcome/ improving-care/emergency-urgent-care/major-trauma/nhs-clinical-advisory-group/

14. Department of Health. Comprehensive Critical Care: A Review of Adult Critical Care Services. London: 2000. http://www.dh.gov.uk/en/Publicationsandstatistics/ Publications/PublicationsPolicyAndGuidance/DH 4006585

15. Baxt WG, Moody P. The impact of advanced prehospital emergency care on the mortality of severely brain-injured patients. J Trauma 1987;27:365-9.

16. Wilden JN. Rapid resuscitation in severe head injury. Lancet 1993;342:1378

17. Baxt WG, Moody P. The impact of a physician as part of the aeromedical prehospital team in patients with blunt trauma. JAMA 1987:257:3246.

18. Lossius HM, Søreide E, Hotvedt R, et al. Prehospital advanced life support provided by specially trained physicians: is there a benefit in terms of life years gained? Acta Anaesthesiol Scand 2002:46:771-8. 
19. Osterwalder JJ. Mortality of blunt polytrauma: a comparison between emergency physicians and emergency medical technicians. J Trauma 2003;55:355-61.

20. Klemen $\mathbf{P}$, Grmec S. Effect of pre-hospital advanced life support with rapid sequence intubation on outcome of severe traumatic brain injury. Acta Anaesthesiol Scand 2006;50:1250-4.

21. Berlot G, Fata CL, Bacer B, et al. Influence of prehospital treatment on the outcome of patients with severe blunt traumatic brain injury: a single-centre study. Eur $J$ Emerg Med 2009;16:312-17.

22. Botker MT, Bakke SA, Christensen EF. A systematic review of controlled studies: do physicians increase survival with prehospital treatment? Scand J Trauma Resusc Emerg Med 2009;17:12.

23. Department of Health. The National Health Service Constitution. London: 2009. http://www.dh.gov.uk/en/Publicationsandstatistics/Publications/PublicationsPolicy AndGuidance/DH 093419

24. Nicholl J, Turner N, Stevens K, et al. A Review of the Costs and Benefits of Helicopter Emergency Ambulance Services in England and Wales: Final report to the Department of Health. Medical Care Research Unit. Sheffield: University of Sheffield, 2003

25. Department of Health. NHS Emergency Planning Guidance: Planning for the Development and Deployment of Medical Emergency Response Incident Teams in the Provision of Advanced Medical Care at the Scene of an Incident. London: 2009. http://www.dh.gov.uk/en/Managingyourorganisation/Emergencyplanning/index.htm

\section{Images in emergency medicine}

\section{Bilateral hip pain as presentation of multiple myeloma}

A 76-year-old man, without systemic disease but with progressive disability due to bilateral hip pain in 1 month, was brought to the emergency department. He denied any episode of trauma and was able to walk during his first visit to the emergency department. Pelvis radiography showed generalised osteopenia along with a bilateral femur neck fracture (figure 1). The patient was admitted to the hospital for bilateral total hip arthroplasty with Moore's prosthesis. Serum protein electrophoresis identified an $M$ protein as a spike in the $\alpha_{2}, \beta$ or $\gamma$ regions and a $\kappa / \lambda$ ratio of 1096. The levels of haemoglobin and serum calcium were 11.5 and $8.5 \mathrm{mg} / \mathrm{dl}$, respectively. Renal function was stable, with a creatinine level of $1.25 \mathrm{mg} / \mathrm{dl}$. Bone marrow biopsy showed that $82.5 \%$ marrow cellularity consisted of plasma cells. A diagnosis of multiple myeloma was made. The patient is

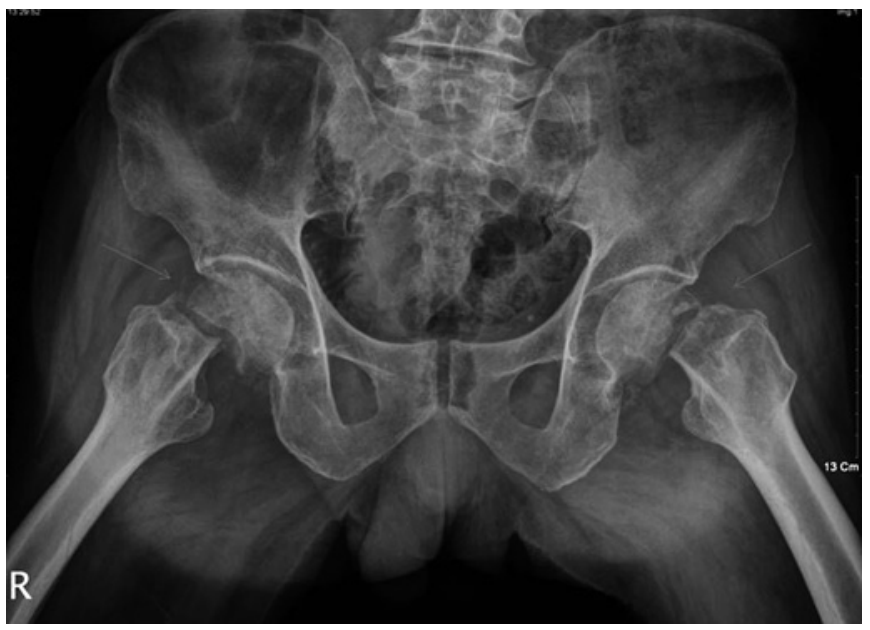

Figure 1 Pelvis radiography shows generalised osteopenia along with a bilateral femur neck fracture (arrow). currently being treated with melphalan and prednisolone and is advised to undergo regular follow-up under stable conditions.

Multiple myeloma is the malignancy of plasma cells and the most common primary cancer of bones in adults that causes end-organ damage such as bone destruction, renal failure, anaemia and hypercalcaemia. ${ }^{1}$ Clinical symptoms on presentation are fatigue, bone pain (especially in the back, long bones, the skull and pelvic bone) and recurrent infections. ${ }^{2}$ Diagnostic criteria are based on the presence of at least $10 \%$ plasma cells on bone marrow biopsy, monoclonal protein in the serum or urine, and evidence of end-organ damage. ${ }^{3}$ Multiple myeloma is still incurable but remission may be achieved with the use of steroids, chemotherapy, thalidomide and stem cell transplantation. The average period of survival of patients with multiple myeloma is approximately 3 years.

\section{Wei-Jing Lee, Walter Wu}

Department of Emergency Medicine, Chi-Mei Medical Center, Tainan, Taiwan, Province of China

Correspondence to Dr Wei-Jing Lee, Emergency Medicine, Chi-Mei Medical Center, 901 Zhonghua Rd, Yongkang District, Tainan 710, Taiwan, Province of China; saab934151@pchome.com.tw

Acknowledgements The authors thank the patient for his consent to participate in this study.

Competing interests None.

Patient consent Obtained.

Contributors Both authors contributed equally.

Provenance and peer review Not commissioned; internally peer reviewed.

Accepted 24 September 2011

Published Online First 11 October 2011

Emerg Med J 2012;29:181. doi:10.1136/emermed-2011-200743

\section{REFERENCES}

1. Kyle RA, Rajkumar SV. Plasma cell disorders. In: Goldman L, Ausiello DAeds. Cecil Textbook of Medicine, 22nd edn. Philadelphia: W.B. Saunders, 2004:1184-95 2. Kyle RA, Rajkumar SV. Multiple myeloma. N Engl J Med 2004;351:1860-73.

3. International Myeloma Working Group. Criteria for the classification of monoclona gammopathies, multiple myeloma and related disorders: a report of the International Myeloma Working Group Br J Haematol 2003:121:749-57. 